Survival and growth of parasitic Maculinea alcon caterpillars (Lepidoptera, Lycaenidae) in laboratory nests of three Myrmica ant species

Nash, David Richard; Als, Thomas Damm; Boomsma, J. J.

Published in:

Insectes Sociaux

DOI:

10.1007/s00040-011-0157-y

Publication date:

2011

Document version

Peer reviewed version

Citation for published version (APA):

Nash, D. R., Als, T. D., \& Boomsma, J. J. (2011). Survival and growth of parasitic Maculinea alcon caterpillars (Lepidoptera, Lycaenidae) in laboratory nests of three Myrmica ant species. Insectes Sociaux, 58(3), 391-401. https://doi.org/10.1007/s00040-011-0157-y 


\title{
Survival and growth of parasitic Maculinea alcon caterpillars (Lepidoptera, Lycaenidae) in laboratory nests of three Myrmica ant species
}

\author{
D. R. Nash • T. D. Als $・$ J. J. Boomsma
}

Received: 25 October 2010/Revised: 7 February 2011/Accepted: 25 February 2011 / Published online: 13 March 2011

(C) International Union for the Study of Social Insects (IUSSI) 2011

\begin{abstract}
The Alcon blue butterfly (Maculinea alcon) parasitizes the nests of several Myrmica ant species. In Denmark, it uses M. rubra and M. ruginodis, but never M. scabrinodis. To further examine the basis of this specificity and local co-adaptation between host and parasite, the pattern of growth and survival of newly-adopted caterpillars of M. alcon in Myrmica subcolonies was examined in the laboratory. M. alcon caterpillars were collected from three populations differing in their host use, and reared in laboratory nests of all three ant species collected from each M. alcon population. While there were differences in the pattern of growth of caterpillars from different populations during the first few months after adoption, which depended on host ant species and the site from which the ants were collected, there was no evidence of major differences in final size achieved. Survival was, however, much higher in nests of $M$. rubra than in nests of $M$. ruginodis and M. scabrinodis, even for caterpillars from a population that is never known to use M. rubra as a host in the field. The caterpillars of M. alcon thus do not show local adaptation in their pattern of growth and survival, but instead show a pattern that may reflect different nestmate recognition abilities of the host ants, related to their sociogenetic
\end{abstract}

D. R. Nash $(\bowtie) \cdot$ J. J. Boomsma

Department of Biology, Centre for Social Evolution,

University of Copenhagen, Universitetsparken 15,

2100 Copenhagen, Denmark

e-mail: DRNash@bio.ku.dk

D. R. Nash · T. D. Als · J. J. Boomsma

Department of Ecology and Genetics, University of Aarhus,

Aarhus, Denmark

T. D. Als

National Institute of Aquatic Resources, Section for Freshwater Fisheries Ecology, Silkeborg, Denmark organisation. The pattern of observed host ant use in the field seems to result from a combination of differences in local host availability and locally adapted infectivity, modulated by smaller differences in survivorship in the nests of the different host ants.

Keywords Host specificity · Encounter - Infection · Exploitation

\section{Introduction}

The proximate mechanisms that determine the specificity of a parasite can be regarded as a series of filters (Combes, 2001). In order to successfully parasitize a particular host species, a parasite must: (1) encounter that host, (2) infect that host by overcoming its self/non-self defences, and (3) successfully convert the resources of the host into new parasites. Selection may act on variation in any of these filters to decrease or increase specificity or to allow host shifts.

The members of the lycaenid butterfly genus Maculinea van Eecke have an unusual life cycle, in which they develop on plants for their first three larval instars, but become social parasites of Myrmica ant colonies in the fourth larval instar. All five European species of Maculinea oviposit on the inflorescences of specific perennial host plants, which flower only in mid summer (Thomas et al., 1998a). The young caterpillars develop quickly to the fourth (final) instar before leaving their food plants in late July or August. They then apparently mimic the larvae of Myrmica Latreille ants to ensure that they are found and adopted by foraging Myrmica workers (Akino et al., 1999; Nash et al., 2008). The caterpillars live inside the ant nest for 10-11 months, gaining some $98 \%$ of their final biomass either as predators 
eating the ant's brood or in a cuckoo-like manner, being actively fed by the ants (Thomas and Elmes, 1998). The caterpillars pupate here, and normally eclose as adults the summer after they were adopted, although some caterpillars may take 2 years to develop (Als et al., 2002; Schönrogge et al., 2000; Thomas et al., 1998b).

On many Maculinea sites, up to eight species of Myrmica forage beneath the Maculinea food plants, all of which may pick up Maculinea caterpillars and take them back to the nest (Elmes et al., 1991a). However, it is only a small subset of these nests from which imagos will eclose, and in many cases this reflects local specialisation on particular Myrmica species as hosts (Als et al., 2002; Tartally et al., 2008).

Surveys carried out from 1997 to 2010 have confirmed that both Myrmica rubra and M. ruginodis are used as host ants by Maculinea alcon in Denmark, and that specificity is not complete for many of the Danish M. alcon populations (Als et al., 2002). Of five populations investigated in detail, one used exclusively $M$. rubra as a host and another exclusively $M$. ruginodis, but the remaining three used both ant species within the same site. No populations, however, parasitized M. scabrinodis, the usual host of $M$. alcon in southern Europe (Elmes et al., 1994), even though this species is common on Danish M. alcon sites (Als et al., 2002). There are clear differences between $M$. ruginodis and M. rubra in terms of colony size (Wardlaw and Elmes, 1996), kin structure (Elmes and Keller, 1993; Seppä, 1996) and glandular chemistry (Akino et al., 1999; Bagnères and Morgan, 1991), which might be expected to select for host specificity. The apparent simultaneous use of two host ant species by some Maculinea alcon populations but not by others therefore raises interesting questions about the evolution and co-adaptation of parasites and hosts. The stable use of two alternative host species would imply that parasite fitness is to some extent independent of host species. The exclusive use of some host-ant species in some sites (despite the presence of the alternative host) suggests that this is not, however, always the case. Selection pressure for host specificity and parasite-host coevolution thus seems to vary geographically (Nash et al., 2008).

In terms of the three filters mentioned above, we have previously shown how encounter rate with different $M y r-$ mica species varies across sites (Als et al., 2002), and that there are significant differences in how easily $M$. alcon caterpillars can overcome the self/non-self recognition systems of their hosts ("initial integration", measured as the time taken for caterpillars of M. alcon to be adopted by laboratory colonies of different Myrmica species), which depend not only on ant species, but also from which population both the $M$. alcon and their host ants are collected (Als et al., 2001). Successful parasitism of an ant nest does not, however, involve simply gaining access to that nest.
Once in the ant colony, a $M$. alcon caterpillar is entirely dependent on its host ants for food, and must continually "persuade" its host ants that it is not a food item, and that it should receive food by trophallaxis ("full integration", Schönrogge et al., 2004; Elmes et al., 2004). The final size achieved by M. alcon butterflies emerging from ant nests is also likely to have a profound effect upon their fecundity and mating success (cf. Elgar and Pierce, 1988). The observed patterns of host specificity in the field may therefore reflect not only variation in the ability to enter host nests, but also variation in the third filter, the ability to survive and grow within such nest. In this study we therefore followed the fates and development of the caterpillars adopted in a previous experiment (Als et al., 2001).

\section{Methods}

This study is an extension of one examining adoption of $M$. alcon caterpillars by colonies of three different Myrmica species, and details of field sites, collection and adoption of M. alcon caterpillars can be found in that paper (Als et al., 2001). Summary details relevant to this study are given below.

Ant colonies and caterpillars were collected at three sites in Denmark differing in Myrmica ant species used as hosts by M alcon. At one site (referred to as RUB throughout this paper), the butterflies used primarily $M$. rubra as a host, at another (RUG), M. ruginodis was used as the exclusive host, and at the third (BOTH) both M. rubra and M. ruginodis were used. Approximately 30 Gentiana pneumonanthe flowers bearing eggs of $M$. alcon were collected from the three field sites in July and August 1998, distributed across the sites to maximise the number of ovipositing females likely to be represented among the eggs. On emergence from the gentian plants, fourth instar caterpillars were weighed and presented to Myrmica colonies for adoption within $1 \mathrm{~h}$. Myrmica rubra, M. ruginodis and M. scabrinodis colonies were collected from each of the field sites, and divided into small experimental subcolonies, with a single queen, 250 workers and either $0.5 \mathrm{~g}$ of mixed ant brood, or if insufficient brood was available, an equal portion of all the brood from its mother colony. Colonies were fed weekly with frozen adult Drosophila and artificial diet (Bhatkar and Whitcomb, 1971), and were provided with ad libitum water.

For the ant species M. rubra and M. ruginodis, experimental nests were set up in a 3-way full factorial design, with caterpillar source site, ant source site and ant species as the three factors. Within each treatment there were five replicate colonies (except for $M$. ruginodis subcolonies from site BOTH receiving caterpillars from site BOTH, 
where an additional replicate was accidentally included). For M. scabrinodis subcolonies, a full factorial design was not used, with caterpillars from each site only being presented to ant colonies collected from the same site. This was done partly for logistical reasons, since it proved impossible to collect sufficient queen-right $M$. scabrinodis colonies in the field for a full factorial design, but mostly because $M$. scabrinodis is not known to be a host of M. alcon in Denmark, so that local adaptation was not expected.

Four caterpillars of $M$. alcon were introduced to each subcolony, and the time taken before they were adopted was recorded (Als et al., 2001). Caterpillars that were not adopted within $48 \mathrm{~h}$ after being offered to the ants were "force-adopted" by placing the caterpillars directly into the ant nest chamber. Any caterpillars that died before adoption (which only occurred if the caterpillars remained unadopted for nearly $48 \mathrm{~h}$ ) were replaced with fresh caterpillars, which were immediately force-adopted. Thus each of the 106 subcolonies started the experiment with four adopted caterpillars of M. alcon.

\section{Measurement of growth and survival}

The survival and growth of caterpillars was assessed at 28-day intervals after adoption, with the exception of day 140 , where data could not be collected for practical reasons. At each census period the number of caterpillars alive in each nest was counted, and each caterpillar weighed to $0.01 \mathrm{mg}$ using a Sartorius balance. Since caterpillars were not marked individually, masses were assigned to individual caterpillars so as to minimise the change in mass between recording periods. Thus it was assumed that the heaviest caterpillar within a subcolony remained the heaviest caterpillar, and if a caterpillar had died, the identity of that caterpillar was assigned by assuming minimal mass change of the surviving caterpillars. Since mean caterpillar masses were used for analysis (see below), it is unlikely that these assumptions introduced any consistent bias into the data. If all the caterpillars within a subcolony had died at any census, that subcolony was removed from the experiment, and the remaining worker ants frozen for later genetic analysis.

Subcolonies were maintained in climate control cabinets with a 12-h light, 12-h dark cycle. Each light phase also had a controlled temperature, which was varied throughout the experiment to reflect external temperature changes. Thus, in October, a "day-time" temperature of $20^{\circ} \mathrm{C}$ and a "nighttime" temperature of $15^{\circ} \mathrm{C}$ were used. In November these were reduced to 15 and $10^{\circ} \mathrm{C}$ respectively, and in December, further reduction to 10 and $5^{\circ} \mathrm{C}$ was made. The cabinets remained at these temperatures until March, when temperatures were increased again to 15 and $10^{\circ} \mathrm{C}$, respectively, and once more to 20 and $15^{\circ} \mathrm{C}$ in May (Fig. 1). This cycle was carried out to reflect soil temperatures in the field, and
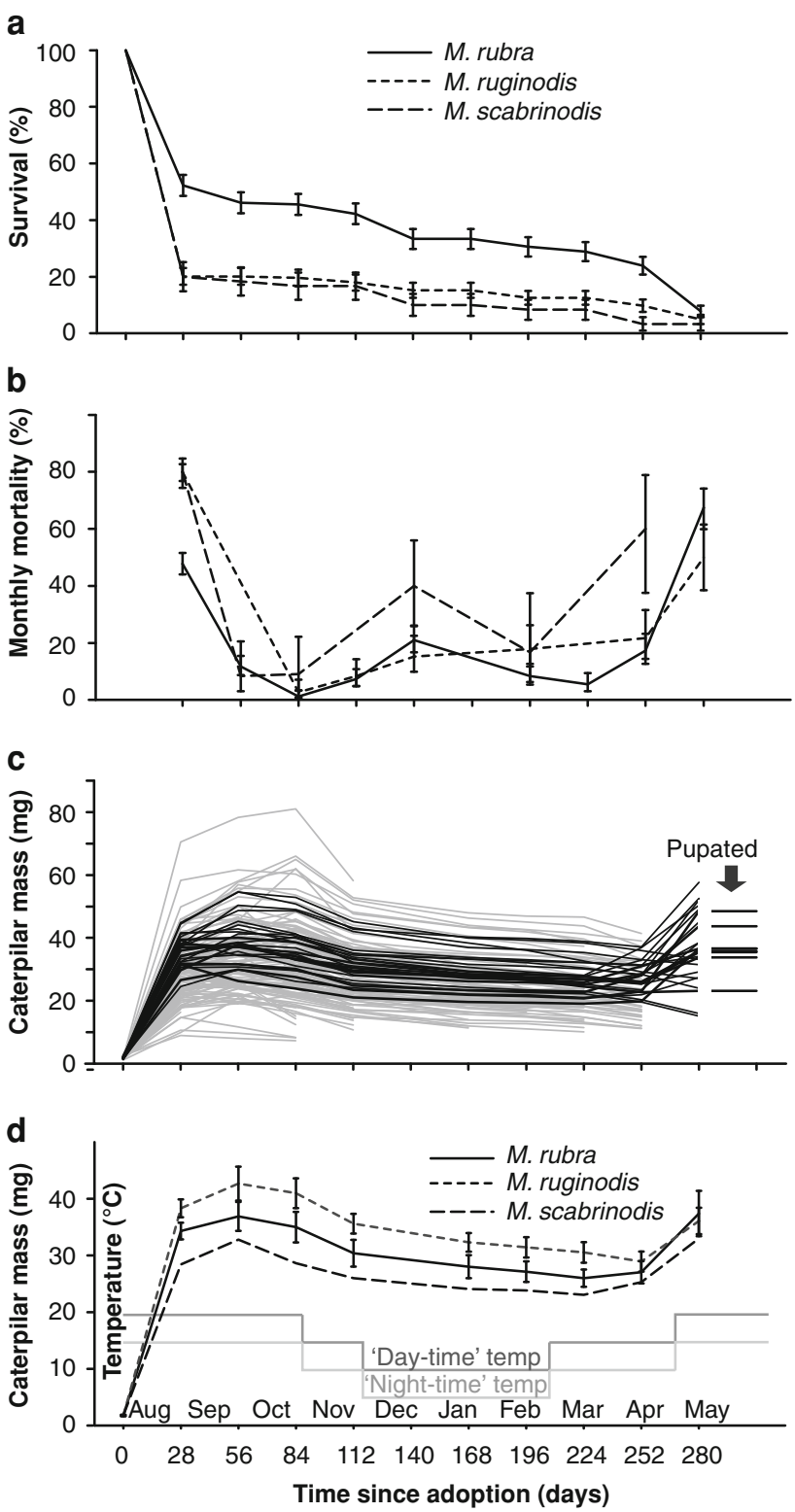

Fig. 1 Survival and growth of M. alcon caterpillars in laboratory nests of three Myrmica species over 280 days after adoption. a Survival curves and $\mathbf{b}$ Monthly mortality rates. Means and standard errors are estimated from binomial GLM using ant subcolonies as replicates in both panels. c Growth curves of all caterpillars. Caterpillars that survived for all 10 census periods are shown as black lines, those dying before census 10 are shown as grey lines. The eight caterpillars that went on to pupate are marked to the right of the graph. d Growth curves of those caterpillars that survived to the last census period in the nests of three different Myrmica species. Mean and standard error of caterpillar mass at each census is based on the subcolony means of these caterpillars. Caterpillars survived to the last census in only a single subcolony of $M$. scabrinodis, so this curve has no error bars. Also shown are the day-time and night-time temperatures of the growth cabinets, and the months of the year

because a period of low winter temperature is thought to be important for the development of Maculinea caterpillars (Wardlaw et al., 1998). 
After 196 days, an estimate was made of the number of surviving worker ants in each remaining subcolony. After 224 days, the subcolonies were transferred to clean nest boxes, and the opportunity was taken to take a more accurate measure of surviving worker numbers. The number of surviving ant brood in each subcolony was also assessed during this transfer.

Censuses were taken until 280 days after adoption. All remaining caterpillars had either died or pupated before the next recording period (308 days). In cases where caterpillars successfully pupated, the subcolony was removed from the climate control cabinet and transferred to a larger butterfly emergence cage, at room temperature, and placed by a window. Grass stems and small sticks were provided within the subcolony to allow any emerging butterflies to climb out of the subcolony and expand their wings.

\section{Statistical analysis}

Since the survival and growth of caterpillars within each subcolony cannot be considered independent, as it is the same worker force that is responsible for providing each caterpillar with food and with the recognition of other colony members and intruders, subcolonies were used as replicates in all analyses. Since female $M$. alcon often lay batches of eggs on the same host plant (Nowicki et al., 2005), it is likely that offspring of the same female were present in different subcolonies, which may have introduced some unplanned dependencies between subcolonies, if there is a genetic component to integration and growth patterns. However, since we collected G. pneumonanthe plants from across the whole range of each site, and used caterpillars emerging throughout the entire emergence period, we believe these effects would have been small, and evenly distributed across treatments.

For the analysis of survival, each subcolony was characterised by the median day of death of the four caterpillars (or pupae) within the subcolony. Survival analysis was carried out using Cox's proportional hazard model, as implemented in JMP 8.02 for Macintosh (SAS Institute inc., 2009). Censoring of data was only necessary for one ant colony that yielded two adult butterflies. Two separate survival analyses were carried out, one, including only host species $M$. rubra and $M$. ruginodis, allowed a full factorial analysis, using ant source, caterpillar source and ant species, plus all their interactions, as explanatory variables. In addition, the median adoption time and mean mass of the caterpillars when adopted were included as covariates. A second survival analysis was carried out which also included M. scabrinodis, and which only used the subset of data from ant subcolonies that were caring for M. alcon from the same site (i.e. the ant source and caterpillar source were the same). In this case source population and ant species, plus their interaction were included as factors, and once again median adoption time and mean mass of the caterpillars when adopted were included as covariates. Mortality for each census period was also compared between species using a generalised linear model with binomial errors, with the number of caterpillars dying in each subcolony in that census period as the dependent variable and the number of caterpillars that survived from the previous census period as the binomial denominator. Analysis was carried out in JMP 8.02 .

To examine whether there was any effect of caterpillar mass on likelihood of survival from one census period to the next, the masses that were recorded at the previous census period for those caterpillars that had died at each census were compared with the masses recorded at the previous census period for those that survived. Comparison was made using Welch's approximate $t$ test (Zar, 1996), since variances were often very different between the two groups.

Since caterpillars were dying throughout the experiment, and growth could only be measured for living caterpillars, detailed growth patterns were only examined over the first six recording periods. This length of time was chosen because for the host species $M$. rubra and M. ruginodis, caterpillars survived in at least two subcolonies for this period in every combination of ant source and caterpillar source, except one (caterpillars from the RUB site reared by $M$. ruginodis from the RUB site), where all caterpillars had died before the first recording period. The number of caterpillars surviving in the smaller number of $M$. scabrinodis nests was too low to allow inclusion of these data in the full analysis.

Growth curves were examined using repeated measures analysis of variance. Ant source, caterpillar source and ant species were included as explanatory factors, plus their twoway interactions. The three-way interaction between these three explanatory variables could not be tested directly, because of the missing growth data in one of the cells of the interaction matrix (see above). To test only the three-way interaction, these missing data were replaced with values estimated from the remainder of the data with an appropriate reduction in degrees of freedom (Sokal and Rohlf, 1995). Since the nutrition of $M$. alcon caterpillars is dependent on the number of worker ants available to feed them, the number of worker ants estimated at day 196 was fitted as a covariate in all analyses.

\section{Results}

Of the 430 caterpillars originally adopted, 23 survived until day 280, in 14 different subcolonies. Of the 23 survivors, eight successfully pupated, five later emerging as adults. For the survival analysis, the only significant effect was host ant 
Table 1 Results of survival analysis based on the Cox's proportional hazard model

\begin{tabular}{llll}
\hline Source & $d f$ & $\mathrm{~L}-\mathrm{R} \chi^{2}$ & $p$ \\
\hline Analysis I, M. rubra and $M$ ruginodis only & & & \\
Caterpillar source & 2 & 2.02 & 0.36 \\
Ant source & 2 & 0.43 & 0.81 \\
Ant species & 1 & 6.43 & $\mathbf{0 . 0 1 1}$ \\
Caterpillar source $\times$ Ant source & 4 & 2.41 & 0.66 \\
Caterpillar source $\times$ Ant species & 2 & 1.27 & 0.53 \\
Ant source $\times$ Ant species & 2 & 2.97 & 0.23 \\
Caterpillar source $\times$ Ant source $\times$ ant species & 4 & 5.38 & 0.25 \\
Adoption time & 1 & 0.24 & 0.63 \\
Adoption mass & 1 & 0.27 & 0.60 \\
Analysis II, including $M$. scabrinodis & & & \\
Caterpillar source & 2 & 1.64 & 0.44 \\
Ant species & 2 & 9.67 & $\mathbf{0 . 0 0 7 9}$ \\
Caterpillar source $\times$ Ant species & 4 & 1.77 & 0.78 \\
Adoption time & 1 & 0.98 & 0.32 \\
Adoption mass & 1 & 0.16 & 0.69 \\
\hline
\end{tabular}

The significance of each term was assessed using the likelihood-ratio (L-R) chi-squared test. Significant $p$ values are shown in bold

species (Table 1), with greater mortality in subcolonies of M. scabrinodis and M. ruginodis compared with M. rubra (Fig. 1a). There were no significant population specific effects or correlations with adoption time or mass at adoption. Rate of mortality was highest during the first 28 days after adoption, exceeding $80 \%$ for $M$. ruginodis and $M$. scabrinodis, and then dropped to a low level over the winter period before increasing again in the spring (Fig. 1b). Mortality only differed significantly between host ant species during the first census period (Likelihood-ratio (L-R) $\left.\chi^{2}=15.84, d f=2, p<0.001\right)$, after which the mortality during each census did not differ between host species (L-R $\left.\chi^{2}=2.15, d f=2, p=0.342\right)$, but was consistently different between census periods (L-R $\chi^{2}=25.0, d f=7$, $p<0.001)$. The interaction between host species and census period was not significant $\left(\mathrm{L}-\mathrm{R} \chi^{2}=14.5, d f=14\right.$, $p=0.412$ ).

The caterpillars that died at each census were generally smaller at the previous census than those that survived (Table 2), the only non-significant comparisons being for those censuses at which three or fewer caterpillars died, and that where there was 56 days between censuses.

The estimates of worker numbers made after 196 days were found to be low compared to the accurate numbers recorded after 224 days, reflecting the difficulties inherent in counting worker ants clustering around the queen, brood and caterpillars in the subcolonies. The two measures were, however, highly correlated $(r=0.813, p<0.001)$. The estimates at day 196 were therefore multiplied by a factor of 1.39 , the slope of the regression line through the origin between the worker estimate at day 196 and the accurate measurements at day 224. These revised estimates ranged from 56 to 250 surviving workers per subcolony (mean \pm SE: $124 \pm 7.33$ ).

At day 224, only two of the 50 surviving subcolonies had any ant brood present. Both of these subcolonies had only one surviving caterpillar, the other three having died before the first census.

The overall growth curves for those caterpillars that survived up to day 280 are shown in Fig. 1c and d. This shows a pattern of increase in caterpillar mass up to 28 or 56 days after adoption, followed by a slow decline during the winter months, while the caterpillars were in diapause. Caterpillar mass increased once more in the period before pupation in the spring. The same general pattern is shown by all caterpillars surviving until day 168 (Fig. 2), but the larger sample size here allowed a more extensive analysis of the data.

Table 2 The total number of caterpillars recorded as living or dead at each census, and their mass recorded at the previous census

\begin{tabular}{|c|c|c|c|c|c|c|}
\hline \multirow[t]{2}{*}{ Census (day) } & \multicolumn{2}{|c|}{ No of caterpillars } & \multicolumn{2}{|c|}{ Mean mass at previous census $( \pm \mathrm{SE}) \mathrm{mg}$} & \multirow[t]{2}{*}{$t$} & \multirow[t]{2}{*}{$p$} \\
\hline & Alive & Dead & Living & Dead & & \\
\hline $1(28)$ & 131 & 199 & - & - & - & - \\
\hline $2(56)$ & 120 & 11 & $30.94 \pm 0.83$ & $25.03 \pm 1.90$ & 2.85 & 0.013 \\
\hline $3(84)$ & 118 & 2 & $34.05 \pm 1.00$ & $25.66 \pm 3.86$ & 2.10 & 0.26 \\
\hline $4(112)$ & 109 & 9 & $34.25 \pm 1.10$ & $16.24 \pm 3.13$ & 5.42 & $<0.001$ \\
\hline $6(168)$ & 88 & 21 & $29.42 \pm 0.92$ & $26.00 \pm 2.53$ & 1.27 & 0.22 \\
\hline $7(196)$ & 78 & 10 & $27.01 \pm 0.89$ & $19.18 \pm 1.87$ & 3.78 & 0.002 \\
\hline $8(224)$ & 75 & 3 & $26.04 \pm 0.90$ & $24.00 \pm 0.43$ & 0.45 & 0.69 \\
\hline $9(252)$ & 59 & 16 & $26.13 \pm 0.99$ & $20.33 \pm 1.48$ & 3.26 & 0.003 \\
\hline $10(280)$ & 23 & 36 & $27.97 \pm 1.09$ & $22.10 \pm 1.34$ & 3.39 & 0.001 \\
\hline
\end{tabular}

Previous masses of living and dead caterpillars are compared using Welch's approximate $t$ test, which allows different variances in the two samples. Significant $p$ values are shown in bold 

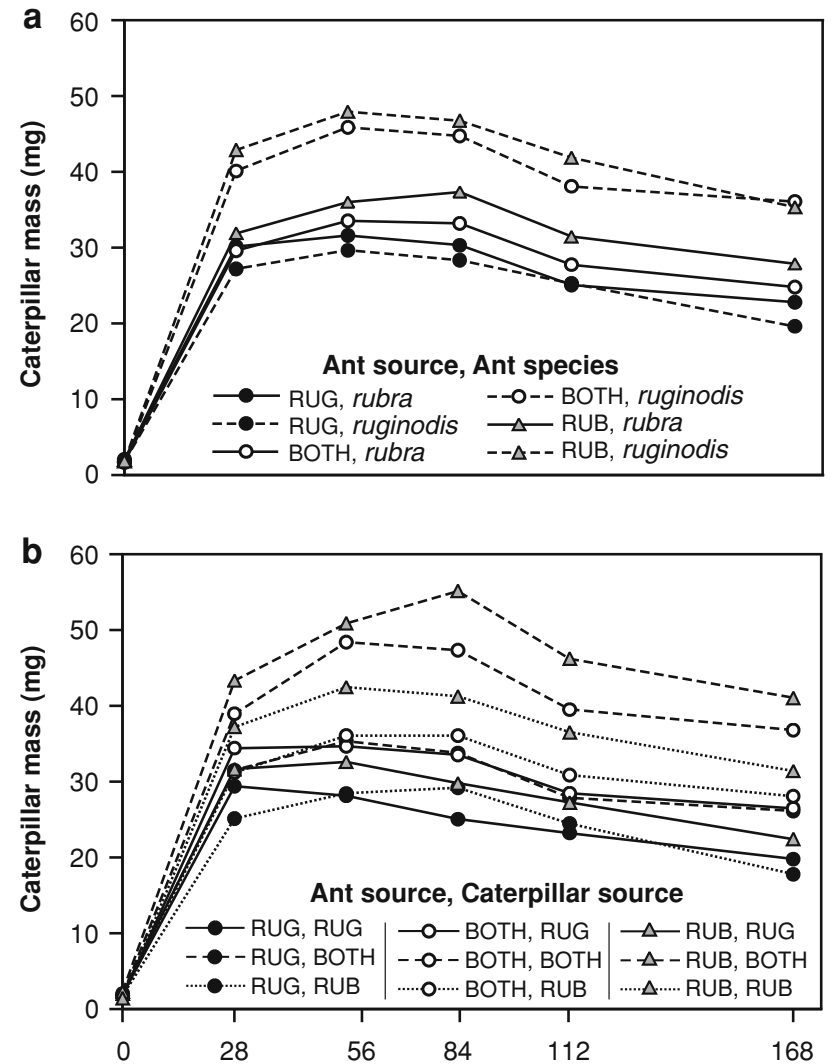

C

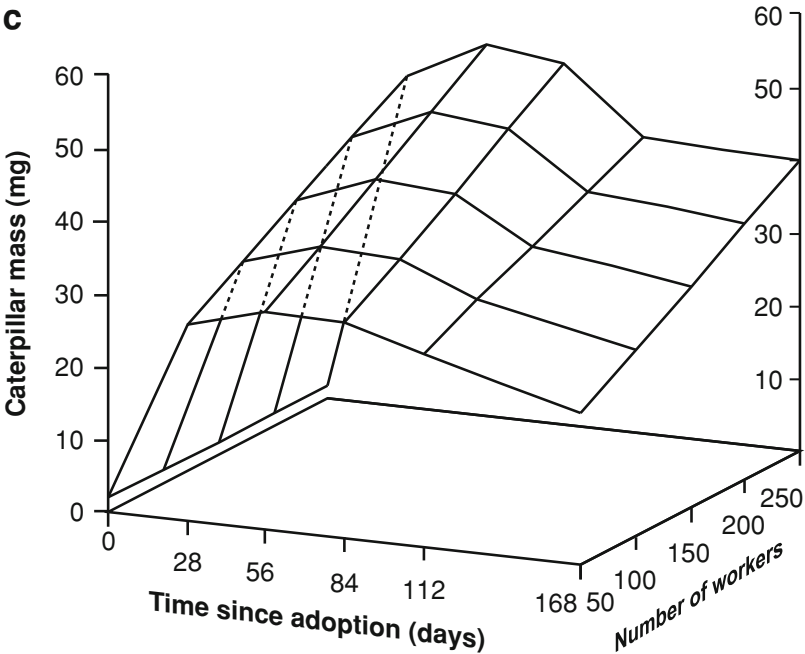

Fig. 2 Growth curves of caterpillars surviving up to day 168, shown as least-squared means for the ant subcolonies in each treatment. Ants and caterpillars were derived from one of the three sites RUB, RUG or BOTH. a The effect of ant source and ant species. b The effect of ant source and caterpillar source. $\mathbf{c}$ The effect of worker number estimated at day 168

Including the synthetic data for caterpillars from the RUB site reared by $M$. ruginodis from the RUB site, the three-way interaction between caterpillar source, ant source and ant species was found to be non-significant $\left(F_{3,16}=0.54, p=0.66\right)$, as was the interaction between
Table 3 Results of analysis of the growth curves of caterpillars from 0 to 168 days after adoption, based on repeated measures analysis of variance

\begin{tabular}{lrrr}
\hline Source & $d f$ & \multicolumn{1}{l}{$l$} & \multicolumn{1}{l}{$p$} \\
\hline Between-subcolony effects & & & \\
Caterpillar source & 2,19 & 5.50 & 0.013 \\
Ant source & 2,19 & 4.26 & 0.019 \\
Ant species & 1,19 & 3.81 & 0.066 \\
Caterpillar source $\times$ Ant source & 4,19 & 0.95 & 0.45 \\
Caterpillar source $\times$ Ant species & 2,19 & 1.39 & 0.27 \\
Ant source $\times$ Ant species & 2,19 & 2.05 & 0.16 \\
Worker number & 1,19 & 5.09 & 0.036 \\
Within-subcolony effects & & & \\
Time & 5,15 & 7.65 & $<0.001$ \\
Time $\times$ Caterpillar source & 10,30 & 5.43 & $<0.001$ \\
Time $\times$ Ant source & 10,30 & 3.88 & 0.002 \\
Time $\times$ Ant species & 5,15 & 2.11 & 0.12 \\
Time $\times$ Caterpillar source $\times$ Ant source & 20,50 & 1.85 & 0.040 \\
Time $\times$ Caterpillar source $\times$ Ant species & 10,30 & 1.73 & 0.12 \\
Time $\times$ Ant source $\times$ Ant species & 10,30 & 3.23 & 0.006 \\
Time $\times$ Worker number & 5,15 & 8.74 & $<0.001$ \\
& &
\end{tabular}

For the between-subcolony effects, exact $F$ tests are given, and for the within-subcolony effects, approximate $F$ tests based on Wilks' lambda are given. Significant $p$ values are shown in bold

this and time in the within-subject analysis (Approximate $F_{15,35}=0.46, p=0.96$ ). Hence, the results of the repeated measures analysis of variance with only two-way interactions and not utilising synthetic data are presented in Table 3, with graphs showing the significant effects in Fig. 2.

The significant between-subcolony effects in the repeated measures analysis of variance reflect differences in overall mass between caterpillars in different treatments. There were significant effects of caterpillar source (caterpillars that originated from the BOTH population were heavier than those from the RUB and RUG populations) and ant source (caterpillars in nests of ants form the RUG site were generally smaller than those from the other sites), and an effect of ant species that was close to significance (caterpillars in $M$. ruginodis nests tended to be somewhat heavier than those in M. rubra nests). There was also a significant effect of worker number on average caterpillar mass (higher numbers of workers surviving up to day 168 were correlated with higher caterpillar mass) but no interactions between main effects were significant.

The significant within-subcolony effects in the repeated measures analysis of variance reflect significant differences in the patterns of growth over time for caterpillars in the different treatments, and all involve an interaction with the time variable. This mostly reflects differences in the time at 
which caterpillars in each treatment attained their maximum mass. There were significant within-subcolony effects of caterpillar source (caterpillars from the RUG site achieved their maximum mass within the first 28 days, while those from the other sites achieved their maximum recorded mass between 56 and 84 days after adoption), ant source (caterpillars raised in nests of ants from the RUG site also tended to attain their maximum mass earlier), and the interaction between these (the time that caterpillars from each site achieved maximum size was different when in nests of ants from the different sites). There was also a significant interaction between ant source and ant species, reflecting a different pattern of growth of caterpillars in the nests of $M$. rubra and $M$. ruginodis from the different sites (e.g. caterpillars in nests of $M$. rubra from the RUB site achieved their maximum mass later than the others, and the mass loss between days 112 and 168 of caterpillars in M. ruginodis nests was less than that of caterpillars in M. rubra nests for the BOTH site, but greater for the RUB and RUG sites). The significant effect of worker number means that the effect of number of workers on caterpillar mass varied with time. Ignoring the day of adoption, where worker number could have no effect on caterpillar mass, the mean increase in caterpillar mass that an additional worker ant contributed varied between $0.09 \pm 0.05$ (SE) mg 112 days after adoption and $0.15 \pm 0.06 \mathrm{mg} 56$ days after adoption.

The mean masses achieved by the caterpillars in the 14 subcolonies with caterpillars surviving to the last census at day 280 were not different for any of the main effects (ANOVA; Caterpillar source: $F_{2,6}=0.42, p=0.67$; Ant source: $F_{2,6}=0.25, p=0.78$; Ant species: $F_{2,6}=1.12$, $p=0.38)$ and were not correlated with number of workers at day $168\left(F_{1,6}=1.82, p=0.23\right)$. Their distribution in the experiment was too sparse to allow any interactions to be tested.

\section{Discussion}

\section{Growth}

The pattern of development of $M$. alcon, and its conspecific or close relative $M$. rebeli (Als et al., 2004), within the nests of their Myrmica host ants have previously been investigated by Elfferich (1963), Elmes et al. (1991b), Thomas et al. (1998b), Schönrogge et al. (2000) and Sielezniew and Stankiewicz (2007). All five studies generally found the same pattern of growth as observed in this study, with an initial increase in caterpillar mass shortly after adoption, followed by a slow decline during the winter months, and a second increase in the spring prior to pupation, which seems to be a pattern common to all Maculinea (cf. Witek et al., 2011).
It is interesting to note, however, that the mass attained by $M$. alcon caterpillars in the first 100 days of our experiment was 2-3 times that observed by Schönrogge et al. (2000) and around 8 times that observed by Sielezniew and Stankiewicz (2007) for M. alcon over 8 weeks. The difference between our results and those of Schönrogge et al., may have been because the number of worker ants available to provide food for each caterpillar was higher in our experiment (initially 250 workers for 4 caterpillars) than theirs (7-20 workers per caterpillar). The importance of worker number for growth of caterpillars of $M$. alcon is reflected in the significant positive correlation between the mass of caterpillars during the first 168 days of the experiment, and the number of workers surviving in each subcolony assessed at day 196. This relationship is not unexpected, since the caterpillars are dependent on the worker ants for nutrition. While $M$. alcon can feed directly on ant brood as well as on regurgitations from worker ants (e.g. Elfferich, 1963), no ant brood remained in the vast majority of subcolonies. The lower effect of worker numbers on caterpillar mass at day 112 compared with day 56 probably reflects the relative inactivity of workers during the colder winter months.

Difference in worker numbers cannot, however, explain the difference between our results and those of Sielezniew and Stankiewicz (2007), whose study also used 200-250 workers per subcolony with 3-6 larvae, and under similar conditions. Instead, the pattern of growth that we observed for M. alcon is more similar to that observed by Sielezniew and Stankiewicz for $M$. rebeli, suggesting that growth strategy of $M$. alcon can vary between sites, perhaps to exploit phenological differences in their host plants (Gotthard, 2008) or as adaptation to different host ants. In this regard it is notable that the $M$. alcon examined by Sielezniew and Stankiewicz use $M$. scabrinodis as a primary host, and that for the different populations examined by Schönrogge et al. (2000), those that exploited M. scabrinodis tended to enter diapause earlier and at a lower mass than those exploiting $M$. rubra and $M$. ruginodis.

M. alcon is often found in large numbers within Myrmica colonies in the field, up to 98 caterpillars in a single nest of M. rubra being recorded at the BOTH site (Als et al., 2002). $M$. alcon caterpillars are therefore thought to suffer intense intraspecific contest competition within their host ant colonies (Thomas and Elmes, 1998; Thomas et al., 1998b, 1993). Thomas and Elmes (1998) suggested for the closely related Maculinea rebeli that the number of ant workers available to provide food to each larva was critical for survival, estimating that a ratio of about 50 workers per caterpillar was required. Thus it might be expected that the ratio of surviving worker ants to surviving caterpillars may explain more of the variation in caterpillar mass than the absolute number of workers. Assuming that mortality of 
worker ants was linear between the day of adoption and day 196, a rough estimate could be made of the ratio of worker ants to caterpillars in each subcolony at each census, which ranged from 26 to 250 workers per caterpillar. However, this showed no significant correlation with the mean mass of surviving caterpillars for any census, although the correlation was always positive (the product-moment correlation coefficient ranged from 0.06 to 0.21 , all $p>0.2$ ).

The effects of the different treatments on growth up to day 168 are complex, but show some interesting patterns. The clearest of these is that the pattern of growth of caterpillars from the RUG population is rather different from the pattern of growth of the caterpillars from the other two populations (reflected in the significant effect of caterpillar source in both between subcolony and within-subcolony analyses). Caterpillars from the RUG population enter diapause earlier and at a lower mass than those from the RUB and BOTH populations, and attain a lower overall mass, at least during the first 168 days of the experiment. Such variation in growth pattern is also shown for the $M$. alcon caterpillars collected from different populations by Schönrogge et al. (2000), where those from one Spanish site (Castro Urdiales) entered diapause earlier, and had a lower overwinter mass than those from a second Spanish site (Soria), which were again earlier and lighter than those from Denmark and the Netherlands.

The significant effect of ant source and the time by antsource interaction means that caterpillars achieve different overall size and different patterns of growth in nests of ants from the different sites, regardless of which ant species is hosting them. This presumably reflects convergence between $M$. rubra and $M$. ruginodis in some aspect of their ecology at the various sites. Caterpillars raised by ants from the RUG site are generally smaller than those raised by ants from the other two sites. This may well reflect the rather different habitat at the RUG site, where, for example, vegetation is generally much higher than at the other two sites, presumably resulting in rather different feeding niches for the ants at this site. The significant within-subcolony effect of the interactions between ant source and ant species suggests that this convergence is not complete for all sites, however, and may be interpreted as divergence in the interaction between $M$. alcon and ants of the same species that originate from different sites. Such a pattern can result from local coevolution of hosts and parasites (Thompson, 2005; Nash et al., 2008). A significant interaction between site and ant species in the size of prepupal caterpillars is also found in the field (Als et al., 2002).

The significant within-subcolony effect of the interaction between ant source and caterpillar source suggests that the inherent growth patterns of the caterpillars from the different sites interact with the feeding behaviours of the ants from the different sites in a complex manner. However, the lack of any significant interaction involving caterpillar source and ant species, either between or within subcolonies, is notable. Such an interaction would be expected if the different populations of $M$. alcon, which exploit different host ant species, have growth patterns that are adapted to these hosts. There is therefore no evidence of local adaptation in growth patterns by M. alcon.

The growth patterns of caterpillars during the first 168 days after adoption may have little to do with the final size achieved by adult M. alcon. Schönrogge et al. (2000) showed that despite large differences in the growth trajectory of caterpillars of $M$. alcon from different sites, the final size achieved by caterpillars just before pupations was similar for all sites, with differences in pre-winter growth being compensated for by complementary differences in spring growth. Our limited data on growth up to day 280 also support this finding (Fig. 2), as does the observation that site by ant species differences in prepupal caterpillar size in the field are not reflected in pupal masses (Als et al., 2002). Thus, the differences in growth pattern observed up until day 168 may have few if any fitness consequences, and may, therefore be selectively neutral.

A proportion of the caterpillars of $M$. alcon, and its close relative $M$. rebeli do not pupate in the spring of the year after adoption, but continue their development in their host ant colonies for a further year (Als et al., 2002; Schönrogge et al., 2000; Thomas et al., 1998b). The factors controlling pupation decisions are complex, but such caterpillars are generally smaller than those that pupate. The fact that all caterpillars in our experiment either died or pupated before 308 days after adoption would initially suggest that no slow developers were present. Although there seems to be a genetic component to the developmental response of fast and slow developers (Thomas et al., 1998b), there also seems to be an environmental component based on resource availability (Witek et al., 2006). Some of the differences that we found in growth patterns between different treatments could therefore potentially reflect different proportions of caterpillars with genetic disposition for fast and slow growth.

The eight pupae that resulted from our experiment were not weighed, but they were much smaller than pupae found in the field, which was reflected in the small size of the five adults that successfully emerged (Mean \pm SE forewing length: Experimental adults: $14.6 \pm 0.29 \mathrm{~mm}$; five randomly chosen adults that emerged from pupae collected in the field and kept under similar conditions: $17.7 \pm$ $0.37 \mathrm{~mm} ; t$ test: $\left.t_{8}=-6.54, p<0.001\right)$. This seems to have resulted primarily from poor growth in the spring, and is not unusual for Maculinea raised in the laboratory (Sielezniew and Stankiewicz, 2007; Tartally, 2005; Witek et al., 2010). This may reflect the small number of surviving worker ants available to feed caterpillars during their period of rapid 
growth in the spring, or the generally low quality of the laboratory diet compared with the flush of food available to ants in the field in the spring. This emphasises that while we expect the relative patterns of development observed in our study to reflect differences in the interaction with different host ant species and populations, caution must be used when extending these results to the field, where food availability and microclimatic conditions can be quite different and much more variable.

\section{Survival}

The pattern of survival of $M$. alcon caterpillars was very clear, with higher survival in nests of $M$. rubra compared to caterpillars in nests of M. ruginodis and M. scabrinodis. Caterpillars that died between censuses generally had significantly lower masses at the previous census than those that survived (Table 2). However, the pattern of mortality did not simply reflect different caterpillar masses in the nests of the different host ants, since although there was an effect of ant species in the analysis of growth patterns that was close to significant (Table 3), caterpillars were generally larger in nests of $M$. ruginodis not M. rubra.

A previous study on the time taken for the subcolonies used in this experiment to adopt the caterpillars offered to them (Als et al., 2001) showed evidence of local adaptation of $M$. alcon populations to their local host ants. The finding that survival was highest in the nests of $M$. rubra, even for the RUG population, where this species is not used as a host, is therefore rather surprising at first sight. It suggests that very different mechanisms are used to survive and grow within the host Myrmica nests than are used for entering the host nests, which is also confirmed by the lack of any correlation between survival and adoption time (Table 1).

Being adopted into a host ant nest appears to primarily depend on the degree of chemical mimicry of the host ant larvae that a caterpillar displays (Akino et al., 1999; Nash et al., 2008). Once inside the host ant nest, the M. alcon caterpillar has to obtain its food by soliciting regurgitations from worker ants, while at the same time avoiding ant predation. The latter is also probably achieved through chemical integration into the host colony, since surface chemistry is the primary mechanism used by ants to recognise non-nestmates. However, once inside the ant nest, caterpillars of $M$. alcon may be able to rely more on passively acquiring the colony odour from other members of the ant colony rather than the active production of mimetic compounds that is necessary for adoption, although for the closely related species, $M$. rebeli, there is some evidence that mimetic cuticular compounds may also be produced after adoption (Schönrogge et al., 2004).

M. rubra is a highly polygynous (Elmes and Keller, 1993; Seppä, 1996) and polydomous (Walin et al., 2001;
Seppä and Walin, 1996) species compared to other Myrmica species. Since surface chemistry of ants has significant genetic and environmental components (Van Zweden and d'Ettorre, 2009), members of a single colony of $M$. rubra are likely to show a greater variation in surface chemistry than other Myrmica species, as there will be a greater number of matrilines present, and different subnests of the same colony are likely to diverge in surface chemistry due to differences in microclimate. Thus, it is likely that the nestmate recognition system of $M$. rubra is inherently less rigid than that used by other Myrmica species, allowing a greater degree of dissimilarity before a stranger is rejected as a non-nestmate (Nash and Boomsma, 2008). Thus, the greater survival of $M$. alcon in the nests of M. rubra may well represent exploitation of the less refined recognition system of this host species. Als et al. (2001) also found a trend for faster adoption of M. alcon caterpillars by $M$. rubra colonies for allopatric populations, although this was not found sympatrically, where local adaptation meant that the local host ant adopted caterpillars most quickly. A similar pattern of greater survival of caterpillars in the nests of more polygynous nests may also exist in Maculinea teleius (Witek et al., 2011), although small sample sizes for some host species in that study meant this difference was not significant.

\section{Host specificity}

Our results show an approximately doubled probability of survival of caterpillars of $M$. alcon in nests of $M$. rubra compared with the alternative host species $M$. ruginodis and M. scabrinodis, independent of the population from which the ants were derived. However, of the three filters that determine host specificity (encounter, infection and exploitation), it is the encounter and infection filters that show the greatest variation for Danish M. alcon, with encounter rates varying by a factor of up to 4.5 (Als et al., 2002) and rates of adoption varying by an order of magnitude between host species, and between different populations of the same host (Als et al., 2001). Since each filter acts sequentially on the population of M. alcon, it is, however, the product of the three filters that will ultimately determine the host use of any particular population - which can be visualised as the volume of the cuboid defined by the probability of passing each filter (Fig. 3). The combination of these three filters explains $84.7 \%\left(r^{2}\right.$ of the regression of relative host use on the volume of the cuboids in Fig. 3) of the variation in actual host use across all three sites (Als et al., 2002), whereas encounter rate, infection rate and exploitation rate (within-host survival) separately explain $60.2,49.1$ and $22.3 \%$, and their two-way combinations explain between 46.8 and $78.5 \%$ of the variation. Thus, it appears that although there is significant variation in 


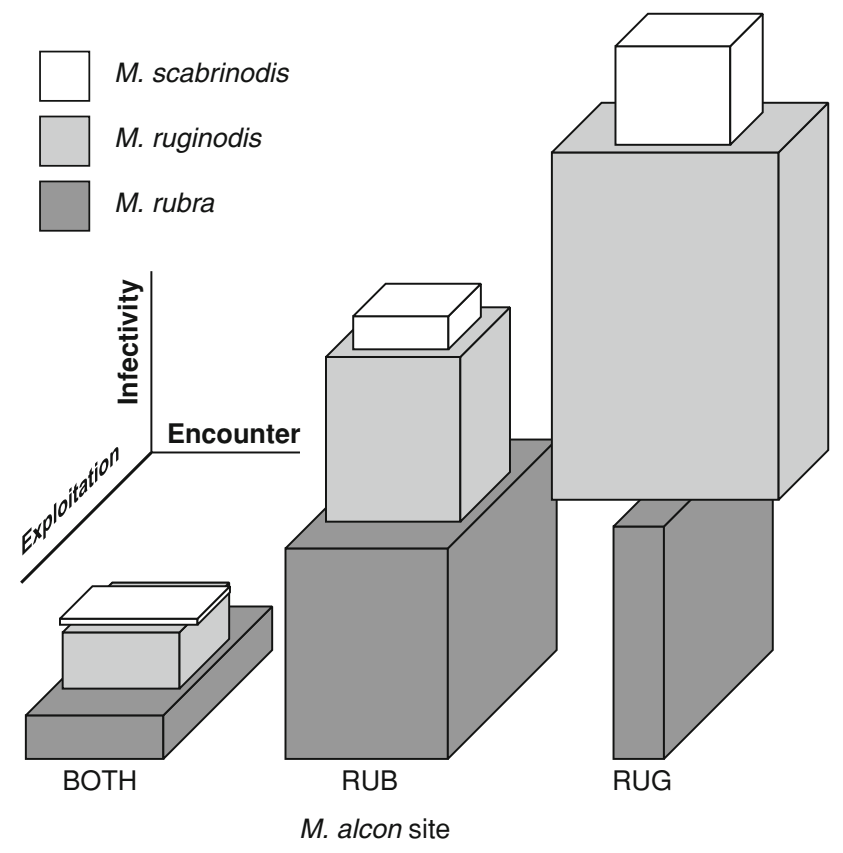

Fig. 3 Comparison of the three filters that determine host specificity for three M. alcon sites and the three potential host Myrmica species. The probability of passing each filter is represented as the distance along each orthogonal axis, with the volume of the cuboid for each ant species proportional to the expected use of that ant species as a host. Values are estimated as survivorship at census 6 from this study for exploitation, proportion of nests of each ant species within $2 \mathrm{~m}$ of gentian plants (Als et al., 2002) for encounter, and rate of adoption of caterpillars of $M$. alcon by laboratory colonies of each local ant species (Als et al., 2001) for infectivity

survivorship of $M$. alcon caterpillars between the nests of different host species, which contributes to host specificity, variations in encounter rate and infectivity are relatively more important.

M. alcon females do not seem to bias their encounter rates with host ant species by using species-specific oviposition cues (Fürst and Nash, 2010; Nowicki et al., 2005), so that they can only have indirect effects on encounter rate through their negative impact on host densities (Nash et al., 2008; Thomas et al., 1998a) and reduced dispersal (Körösi et al., 2008). However, ability to infect M. rubra seems to be under coevolutionary selection, and increases with local availability of M. rubra nests (Nash et al., 2008), so that at least the encounter and infection filters, and as a result, local host specificity, can be quite dynamic.

Acknowledgments We thank Rebekka Gadeberg for information on Maculinea alcon sites, Jes Søe Pedersen, Graham Elmes and Judith Wardlaw for valuable suggestions and comments, Steffen Jørgensen (Randbøl skovdistrikt), Dr. Jur. Beckmann and Nordjyllands statskovdistrikt for allowing fieldwork, Heine Kiesbüy for field assistance and Lone Hoy Jensen and Heine Kiesbüy for assistance in the lab. DRN was supported by an EU Marie Curie fellowship (ERBFMBICT 972161) and by an individual fellowship from the Carlsberg foundation.

\section{References}

Akino T., Knapp J.J., Thomas J.A. and Elmes G.W. 1999. Chemical mimicry and host specificity in the butterfly Maculinea rebeli, a social parasite of Myrmica ant colonies. Proc. R. Soc. Lond. B 266: $1419-1426$

Als T.D., Nash D.R. and Boomsma J.J. 2001. Adoption of parasitic Maculinea alcon caterpillars (Lepidoptera: Lycaenidae) by three Myrmica ant species. Anim. Behav. 62: 99-106

Als T.D., Nash D.R. and Boomsma J.J. 2002. Geographical variation in host-ant specificity of the parasitic butterfly Maculinea alcon in Denmark. Ecol. Entomol. 27: 403-411

Als T.D., Vila R., Kandul N.P., Nash D.R., Yen S.H., Hsu Y.F., Mignault A.A., Boomsma J.J. and Pierce N.E. 2004. The evolution of alternative parasitic life histories in large blue butterflies. Nature 432: 386-390

Bagnères A.G. and Morgan E.D. 1991. The postpharyngeal glands and the cuticle of Formicidae contain the same characteristic hydrocarbons. Experientia 47: 106-111

Bhatkar A. and Whitcomb W.H. 1971. Artificial diet for rearing various species of ant. Fla. Entomol. 53: 229-232

Combes C. 2001. Parasitism: The Ecology and Evolution of Intimate Interactions. University of Chicago Press, Chicago. $552 \mathrm{pp}$

Elfferich N. 1963. Kweekervaringen met Maculinea alcon Schiff. Entomol. Ber. 23: 46-52

Elgar M.A. and Pierce N.E. 1988. Mating success and fecundity in an ant-tended lycaenid butterfly. In: Reproductive Success: Studies of Individual Variation in Contrasting Breeding Systems (CluttonBrock T.H., Ed). Chicago University Press, Chicago, pp 5975

Elmes G.W. and Keller L. 1993. Distribution and ecology of queen number in ants of the genus Myrmica. In: Queen Number and Sociality in Insects (Keller L., Ed). Oxford University Press, Oxford. pp 294-307

Elmes G.W., Thomas J.A., Hammarstedt O., Munguira M.L., Martin J. and van der Made J.G. 1994. Differences in host-ant specificity between Spanish, Dutch and Swedish populations of the endangered butterfly, Maculinea alcon (Denis et Schiff.) (Lepidoptera). Mem. Zool. 48: 55-68

Elmes G.W., Thomas J.A. and Wardlaw J.C. 1991a. Larvae of Maculinea rebeli, a large-blue butterfly, and their Myrmica host ants: wild adoption and behaviour in ant-nests. J. Zool. 223: 447-460

Elmes G.W., Wardlaw J.C. and Thomas J.A. 1991b. Larvae of Maculinea rebeli, a large-blue butterfly and their Myrmica host ants: patterns of caterpillar growth and survival. J. Zool. 224: 79-92

Elmes G.W., Wardlaw J.C., Schönrogge K., Thomas J.A. and Clarke R.T. 2004. Food stress causes differential survival of socially parasitic caterpillars of Maculinea rebeli integrated in colonies of host and non-host Myrmica ant species. Entomol. Exp. Appl. 110: 53-63

Fürst M.A. and Nash D.R. 2010. Host ant independent oviposition in the parasitic butterfly Maculinea alcon. Biol. Lett. 6: 174-176

Gotthard K. 2008. Adaptive growth decisions in butterflies. BioScience 58: $222-230$

Körösi Á., Örvössy N., Batáry P., Kövér S. and Peregovits L. 2008. Restricted within-habitat movement and time-constrained egg laying of female Maculinea rebeli butterflies. Oecologia 156: 455-464

Nash D.R., Als T.D., Maile R., Jones G.R. and Boomsma J.J. 2008. A mosaic of chemical coevolution in a large blue butterfly. Science 319: $88-90$

Nash D.R. and Boomsma J.J. 2008. Communication between hosts and social parasites. In: Sociobiology of Communication: An Inter- 
disciplinary Perspective (d'Ettorre P. and Hughes D.P., Eds). Oxford University Press, Oxford, pp 55-79

Nowicki P., Witek M., Skórka P. and Woyciechowski M. 2005. Oviposition patterns in the myrmecophilous butterfly Maculinea alcon Denis \& Schiffermueller (Lepidoptera: Lycaenidae) in relation to characteristics of foodplants and presence of ant hosts. Pol. J. Ecol. 53: 409-417

Schönrogge K., Wardlaw J.C., Peters A.J., Everett S., Thomas J.A. and Elmes G.W. 2004. Changes in chemical signature and host specificity from larval retrieval to full social integration in the myrmecophilous butterfly Maculinea rebeli. J. Chem. Ecol. 30: 91-107

Schönrogge K., Wardlaw J.C., Thomas J.A. and Elmes G.W. 2000. Polymorphic growth rates in myrmecophilous insects. Proc. R. Soc. Lond. B 267: 771-777

Seppä P. 1996. Genetic relatedness and colony structure in polygynous Myrmica ants. Ethol. Ecol. Evol. 8: 279-290

Seppä P. and Walin L. 1996. Sociogenetic organization of the red ant Myrmica rubra. Behav. Ecol. Sociobiol. 38: 207-217

Sielezniew M. and Stankiewicz A.M. 2007. Differences in the development of the closely related myrmecophilous butterflies Maculinea alcon and M. rebeli (Lepidoptera: Lycaenidae). Eur. J. Entomol. 104: 433-444

Sokal R.R. and Rohlf F.J. 1995. Biometry - 3rd Edition. W.H. Freeman, New York. 887 pp

Tartally A. 2005. Accelerated development of Maculinea rebeli larvae under artificial conditions (Lycaenidae). Nota Lepidopt. 27: 303-308

Tartally A., Nash D.R., Lengyel S. and Varga Z. 2008. Patterns of host ant use by sympatric populations of Maculinea alcon and $M$. 'rebeli' in the Carpathian Basin. Insect. Soc. 55: 370-381

Thomas A., Clarke R.T., Elmes G.W. and Hochberg M.E. 1998a. Population dynamics in the genus Maculinea (Lepidoptera: Lycaenidae). In: Insect Populations in Theory and in Practice (Dempster J.P. and McLean I.F.G., Eds). Kluwer, Dordrecht, The Netherlands, pp 261-290

Thomas J.A. and Elmes G.W. 1998. Higher productivity at the cost of increased host-specificity when Maculinea butterfly larvae exploit ant colonies through trophallaxis rather than by predation. Ecol. Entomol. 23: 457-464
Thomas J.A., Elmes G.W. and Wardlaw J.C. 1993. Contest competition among Maculinea rebeli butterfly larvae in ants nests. Ecol. Entomol. 18: 73-76

Thomas J.A., Elmes G.W. and Wardlaw J.C. 1998b. Polymorphic growth in larvae of the butterfly Maculinea rebeli, a social parasite of Myrmica ant colonies. Proc. R. Soc. Lond. B 265 : 1895-1903

Thompson J.N. 2005. The Geographic Mosaic of Coevolution. Interspecific Interactions. University of Chicago Press, Chicago. $443 \mathrm{pp}$

Van Zweden J.S. and d'Ettorre P. 2009. Nestmate recognition in social insects and the role of hydrocarbons. In: Insect Hydrocarbons Biology, Biochemistry, and Chemical Ecology (Blomquist G.C. and Bagnères A.-G., Eds). Cambridge University Press, Cambridge, UK, pp 222-243

Walin L., Seppä P. and Sundström L. 2001. Reproductive allocation within a polygyne, polydomous colony of the ant Myrmica rubra. Ecol. Entomol. 26: $537-546$

Wardlaw J.C. and Elmes G.W. 1996. Exceptional colony size in Myrmica species (Hymenoptera: Formicidae). Entomologist 115: 191-196

Wardlaw J.C., Elmes G.W. and Thomas J.A. 1998. Techniques for studying Maculinea butterflies: I. Rearing Maculinea caterpillars with Myrmica ants in the laboratory. J. Insect Conserv. 2: 79-84

Witek M., Nowicki P., Śliwińska E.B., Skórka P., Settele J., Schönrogge K. and Woyciechowski M. 2010. Local host ant specificity of Phengaris (Maculinea) teleius butterfly, an obligatory social parasite of Myrmica ants. Ecol. Entomol. 35: 557-564

Witek M., Skórka P., Śliwińska E.B., Nowicki P., Moroń D., Settele J. and Woyciechowski M. 2011. Development of parasitic Maculinea teleius (Lepidoptera, Lycaenidae) larvae in four Myrmica ant host species. Insect. Soc. $\mathbf{5 8}$

Witek M., Sliwinska E.B., Skórka P., Nowicki P., Settele J. and Woyciechowski M. 2006. Polymorphic growth in larvae of Maculinea butterflies, as an example of biennialism in myrmecophilous insects. Oecologia 148: 729-733

Zar J.H. 1996. Biostatistical analysis - 3rd Edition. Prentice-Hall, Upper Saddle River, New Jersey. 662 pp 